\title{
AgNOR count in resting cells (resting NOR) is a new prognostic marker in invasive bladder tumor
}

\author{
Mitsuro Tomobe, Toru Shimazui *, \\ Katsunori Uchida and Hideyuki Akaza \\ Department of Urology, Institute of Clinical Medicine, \\ University of Tsukuba, Tsukuba Ibaraki, Japan \\ Tel./Fax: +81298533223
}

Received 8 January 2001

Accepted 30 March 2001

Purpose: We have previously demonstrated that the AgNOR count in proliferating cells is a predictor of tumor recurrence in superficial bladder tumor (J. Urol. 162 (1999), 63-68). In the present study, we evaluate the type of AgNOR associated with cell cycles as a prognostic factor in invasive bladder tumor using a double staining technique employing both AgNOR and MIB-1 labelling.

Materials and methods: Forty-four paraffin sections of invasive bladder tumors were stained simultaneously with AgNOR and MIB-1. The number of AgNORs in proliferating (MIB-1 positive) or resting (MIB-1 negative) cells were counted from a total of 100 nuclei. Correlations between MIB-1 associated AgNOR count and clinicopathological parameters were statistically analyzed.

Results: The AgNOR count in proliferating cells (proliferating NOR) was significantly higher than that in resting cells (resting NOR) $(p<0.01)$. The resting NOR in tumors with distant metastases was significantly higher than that in tumors without metastases $(p<0.05)$. Patients with a low resting NOR tumor had a better prognosis than those with a high resting NOR tumor, whereas the proliferating NOR was not associated with survival. Survival analysis revealed that the resting NOR was the most powerful prognostic marker in patients with invasive bladder tumor $(p<0.05)$.

Conclusions: Resting NOR had a predictive value in the prognosis of patients with invasive bladder tumor.

Keywords: Transitional cell carcinoma, invasive, resting cell, AgNORs, MIB-1

\footnotetext{
${ }^{*}$ Corresponding author: Toru Shimazui, M.D., Department of Urology, Institute of Clinical Medicine, University of Tsukuba 11-1, Tennodai, Tsukuba-shi, Ibaraki, 305-8575, Japan. Tel./Fax: +81298533223.
}

\section{Introduction}

A number of pathologic features, e.g., tumor grade and stage, have been identified as predictors of prognosis in the patients with bladder tumor. However, the conventional histological grading system is largely dependent on the subjectivity of the pathologist. Furthermore, it is still difficult to predict the biological behavior of individual bladder tumors precisely by the conventional histological grading system alone [1]. Therefore, quantitative methods have been studied to define new clinically relevant variables in place of subjective grading.

Nucleolar organizer regions (NORs) are identical to fibrillar centers on electron microscopic analysis [2, 3] and are visible by silver staining (AgNORs) [4]. Derenzini et al. mentioned that AgNOR quantity is directly related to cell proliferation rate on the study of neuroblastoma cell lines [5]. In many carcinomas, it has been reported that the mean AgNOR number per nucleus (AgNOR count) is associated with tumor aggressiveness and the prognosis of patients [6]. On the other hand, the question of whether or not AgNOR count can demonstrate biological behavior in a bladder tumor is still controversial. Lipponen et al. have reported that the AgNOR count was significantly related to histological grade, clinical stage, and survival in bladder tumor [7]. However, Zambelli claimed that the AgNOR count showed no significant association with either tumor grade, stage or prognosis in bladder tumor [8]. Such conflicting reports are caused by, not only the technical problems of AgNOR stainings, but also the difficulty of determining the significance of the AgNOR regarding tumor behavior or aggressiveness. It is considered that AgNOR count could reflect various phenomena, such as cell proliferation, ploidy or protein synthesis [9]. Furthermore, there are variations in the number of AgNOR from cell to cell. Thus, a new technique that can provide more accurate AgNOR counting to reflect tumor behavior is necessary. 
On the other hand, the fraction of proliferating cells (the growth fraction) in a tumor is an important prognostic feature in many malignancies. One of the most promising immunohistochemical markers for cellular proliferation is $\mathrm{Ki}-67$, which recognizes a nuclear antigen expressed throughout the whole phase of the cell cycle (late G1, S, G2 and M phase) [10]. Bigras et al. performed double staining of AgNOR and Ki-67 in lung carcinomas and evaluated the real proliferating activity combined with AgNOR values (cell proliferation rate) and Ki-67 labelling index (growth fraction) [11]. In bladder tumor, although some investigators have demonstrated a relationship between the number of AgNOR and Ki-67 expression [8,12], no previous studies have simultaneously assessed AgNOR and Ki-67 expression.

We considered that the variation of the AgNOR number from cell to cell could be eliminated by labeling the proliferative cells in association with the cell cycle. Therefore, in a previous study, we established the simultaneous staining technique of AgNOR with Ki-67 using MIB-1 antibody and showed that AgNOR count in proliferating cells (proliferating NOR) had a predictive value for tumor recurrence in a superficial bladder tumor, but not for tumor progression [13]. It is well understood that proliferation rate is associated with the velocity of cell growth, but this is principally different from the malignant potential of a tumor, such as with invasion or metastasis. Given that AgNOR correlates with both proliferation and malignant potential, it is hypothesized that the evaluation of NOR count in resting cells (resting NOR) could reflect the malignant potential of the tumor cells, but not the proliferation. Thus, in this study, we have focused on whether resting NOR is a prognostic marker in patients with invasive bladder tumor.

\section{Materials and methods}

\subsection{Bladder tumor specimens}

Tissue specimens retrospectively obtained from 44 patients (31 male and 13 female) with an invasive bladder tumor between August 1989 and January 1996 (over 6.5 years) were used in this study. All of the specimens were obtained at the time of transurethral resection. The age of these patients ranged from 36 to 89 years, with an average of 69.1 years. The tumors were staged according to the TNM classification of UICC in 1997 [14] and were graded based on the crite- ria of the Japanese Urological Association [15], which is based on the WHO classification. Patients were treated by radical cystectomy, chemotherapy and/or radiation therapy after TUR-Bt, and were followed by morphological studies at six-month intervals. The length of observation ranged from 4 to 103 months with average of 38 months.

\subsection{AgNOR-MIB-1 staining}

The paraffin-embedded blocks were fixed in $10 \%$ neutralized buffered formalin and were cut at a thickness of 4 micrometers. Double staining of AgNOR and MIB-1 was performed as described previously [13]. In each case, a single staining of AgNOR or MIB-1 was prepared as a control.

\subsection{AgNOR counts}

The serial sections stained by single (AgNOR alone) and double staining (AgNOR/MIB-1) were observed under oil immersion at 1,000-fold magnification. Careful focusing was employed to resolve individual AgNORs in clusters as well as satellite AgNORs scattered throughout the nucleus. The number of AgNORs was counted in one hundred cells for MIB-1 positive or negative cells in each tumor. Evaluation of the staining was carried out by two independent observers (M.T. and T.S.) without prior knowledge of the tumor stage or patient profile.

The mean AgNOR number per nucleus (AgNOR count) was calculated for each section. We defined the AgNOR count for MIB-1 positive cells as the proliferating NOR, and for MIB-1 negative cells as the resting NOR. We then compared these AgNOR counts with the ordinary AgNOR count for whole cells (whole NOR). In order to calculate the MIB-1 labeling index (MIB-1 LI), we chose 1000 cells from a well stained area under high magnification and used the following formula: MIB-1 LI $(\%)=$ (total labelled cells $/$ total number of counted cells) $\times 100$.

\subsection{Statistical analysis}

The statistical analysis was performed by an analysis of variance (ANOVA). Differences between the means of each subgroup were evaluated by Sheffe's $F$ test (multiple groups) and the Mann-Whitney $U$-test (two groups). To evaluate the predictive value of the NOR count, the patients were divided into two groups of either a low NOR or high NOR according to their 
average NOR counts. Survival curves were constructed by the Kaplan-Meier method [16] and the differences between the curves were determined by the Log-rank test. A survival analysis was performed using Cox's proportional hazard modeling [17].

\section{Results}

The microscopic findings of double staining with AgNOR and MIB-1 in a bladder tumor are shown in Fig. 1. A positive immunoreaction to the MIB-1 antibody resulted in an intense red coloration of the nucleus. Clearly defined AgNOR dots were observed in MIB-1 positive and negative nuclei.

NOR counts and MIB-1 LI with clinicopathological parameters are summarized in Table 1. Resting NORs from 44 patients ranged from 2.45 to 8.61 , and the average resting NOR was $5.82 \pm 1.72$ (mean \pm standard deviation). The proliferating NORs from 44 patients ranged from 3.20 to 12.76 , and the average proliferating NOR was $8.19 \pm 2.32$. The proliferating NOR average was significantly higher than that of the resting NOR $(p<0.01)$. The average whole NOR from 44 patients was $6.89 \pm 2.16$, and the average of MIB-1 LI was $28.8 \pm 10.3(\%)$.

The correlation between AgNOR counts, MIB-1 LI, and tumor grade and stage is shown in Table ??. The resting NOR in a tumor with metastases was higher than that in a tumor without metastases $(p<0.05)$, whereas the proliferating NOR was not distinguished by metastases. No significant difference of NOR count was observed between grade 2 and 3 and between stage $\mathrm{T} 2$ and T3-4.
Twenty patients had died from bladder tumor during the follow-up period. The highest survival rate was observed in patients with a low resting NOR tumor compared with those with high resting NOR tumor ( $p=0.002$ ) (Fig. 2A). The average resting NOR in patients who died (6.76) was higher than that in the patients who had not $(5.03)(p<0.05)$. In contrast, there was no difference in survival rate between the high proliferating NOR group and the low proliferating NOR group (Fig. 2B).

The results of a univariate analysis using Log-rank test and a multivariate analysis using Cox's proportional hazard regression model are given in Table 3. A proportional hazard regression analysis confirmed that only resting NOR had a predictive value for survival in patients with invasive bladder tumor.

\section{Discussion}

Transitional cell carcinoma of the urinary bladder is comprised of a spectrum of diseases with diverse natural histories. Seventy to eighty percent of these tumors present as superficial lesions that recur in fiftyeighty percent of the patients [18]. Unfortunately, approximately $15-30 \%$ of these recurrent tumors may ultimately demonstrate progression to a higher grade and/or stage. Furthermore, 15-30\% of all patients with bladder tumor initially present with muscle invasive tumors, and of these patients $50 \%$ whose invasive tumors are treated by radical cystectomy will have a relapse with metastatic disease within 2 years [19]. Therefore, the optimal management of invasive bladder tumor re-

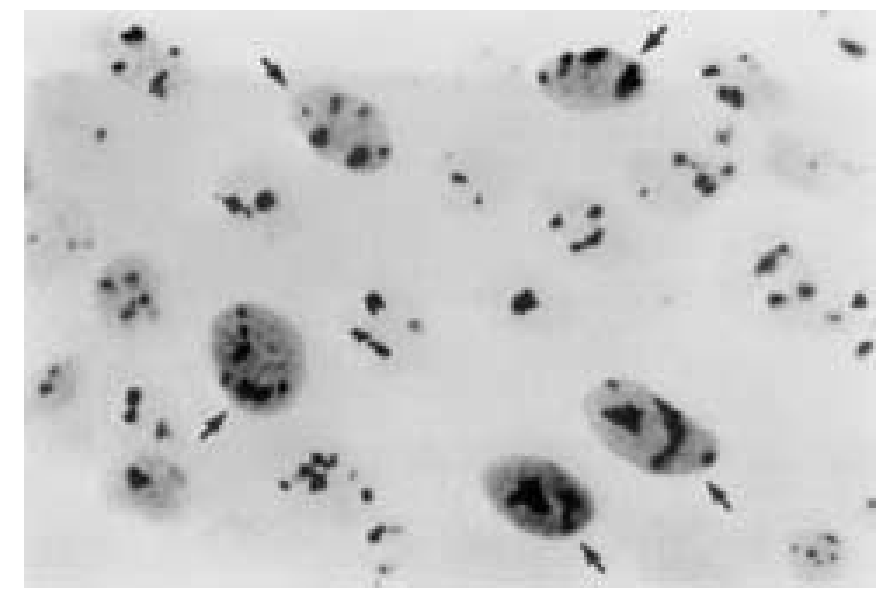

Fig. 1. Bladder tumor (grade 3, invasive) stained with AgNORs and monoclonal antibody MIB-1. A number of AgNOR dots are observed in MIB-1 positive nuclei (arrows) compared with MIB-1 negative nuclei. No counterstaining was performed. Original magnification, $\times 1000$. 
Table 1

NOR counts and MIB-1 LI, clinical and pathological data for each patient

\begin{tabular}{|c|c|c|c|c|c|c|c|c|c|c|c|c|c|}
\hline \multirow[t]{2}{*}{ Case } & \multirow{2}{*}{$\begin{array}{l}\text { Age } \\
(\mathrm{yr})\end{array}$} & \multirow[t]{2}{*}{ Sex } & \multicolumn{3}{|c|}{ Clinical stage } & \multirow[t]{2}{*}{ Grade } & \multicolumn{3}{|c|}{ NOR count } & \multirow{2}{*}{$\begin{array}{c}\text { MIB-1 } \\
\text { L.I. (\%) }\end{array}$} & \multirow{2}{*}{$\begin{array}{l}\text { Treatment } \\
\text { after TUR }\end{array}$} & \multirow[t]{2}{*}{ Prognosis } & \multirow{2}{*}{$\begin{array}{l}\text { Follow } \\
\text { up (mo) }\end{array}$} \\
\hline & & & $\mathrm{T}$ & $\mathrm{N}$ & M & & resting & proliferating & whole & & & & \\
\hline 1 & 82 & $\mathrm{~F}$ & 2 & 0 & 0 & 3 & 6.45 & 9.01 & 7.51 & 33.7 & IAC, $\operatorname{Rad}$ & $\mathrm{D}$ & 22 \\
\hline 2 & 51 & $\mathrm{~F}$ & 2 & 0 & 0 & 2 & 3.70 & 5.05 & 4.30 & 6.7 & Chem, Ope & $\mathrm{D}$ & 35 \\
\hline 3 & 74 & M & 3 & 3 & 1 & 2 & 6.15 & 7.82 & 6.71 & 19.2 & Chem & $\mathrm{D}$ & 11 \\
\hline 4 & 65 & M & 2 & 0 & 0 & 3 & 4.03 & 5.86 & 4.28 & 21.8 & Chem, Ope & A & 21 \\
\hline 5 & 56 & M & 2 & 0 & 0 & 3 & 7.30 & 8.13 & 8.08 & 30.9 & Chem, Rad & A & 52 \\
\hline 6 & 84 & M & 2 & 0 & 0 & 3 & 2.45 & 3.20 & 2.85 & 30.3 & IAC, $\operatorname{Rad}$ & A & 31 \\
\hline 7 & 81 & M & 2 & 0 & 0 & 3 & 5.16 & 6.42 & 5.83 & 28.2 & IAC, $\operatorname{Rad}$ & A & 89 \\
\hline 8 & 67 & M & 2 & 0 & 0 & 2 & 3.63 & 5.60 & 4.35 & 14.3 & IAC, $\operatorname{Rad}$ & A & 7 \\
\hline 9 & 36 & $\mathrm{~F}$ & 3 & 0 & 0 & 3 & 5.66 & 8.36 & 6.68 & 44.5 & Chem, Ope & A & 86 \\
\hline 10 & 53 & M & 3 & 2 & 1 & 3 & 7.63 & 10.25 & 8.77 & 29.4 & Chem, Ope & $\mathrm{D}$ & 15 \\
\hline 11 & 62 & M & 2 & 0 & 0 & 3 & 6.66 & 9.20 & 7.17 & 13.2 & IAC, $\operatorname{Rad}$ & A & 44 \\
\hline 12 & 61 & M & 2 & 0 & 0 & 3 & 4.51 & 6.61 & 5.28 & 23.4 & Chem, Rad, Ope & A & 103 \\
\hline 13 & 68 & M & 2 & 0 & 0 & 3 & 8.35 & 11.15 & 9.65 & 26.9 & Chem, Ope & $\mathrm{D}$ & 36 \\
\hline 14 & 49 & M & 2 & 0 & 0 & 3 & 5.43 & 8.55 & 6.63 & 31.9 & IAC, $\operatorname{Rad}$ & A & 70 \\
\hline 15 & 60 & M & 4 & 0 & 0 & 3 & 5.93 & 7.22 & 6.17 & 28.1 & Chem, Ope & $\mathrm{D}$ & 32 \\
\hline 16 & 64 & M & 2 & 0 & 0 & 3 & 4.37 & 5.60 & 4.67 & 38.1 & IAC, $\operatorname{Rad}$ & A & 74 \\
\hline 17 & 74 & $\mathrm{~F}$ & 4 & 0 & 0 & 3 & 7.35 & 9.65 & 8.60 & 24.1 & IAC, $\operatorname{Rad}$ & $\mathrm{D}$ & 14 \\
\hline 18 & 72 & $\mathrm{~F}$ & 2 & 0 & 0 & 3 & 7.15 & 9.35 & 8.27 & 25.0 & Chem & $\mathrm{D}$ & 5 \\
\hline 19 & 51 & $\mathrm{~F}$ & 2 & 0 & 0 & 3 & 4.15 & 6.10 & 4.27 & 26.8 & IAC, Rad, Ope & A & 93 \\
\hline 20 & 65 & M & 3 & 0 & 0 & 3 & 2.85 & 4.11 & 3.84 & 19.4 & Chem, Ope & A & 6 \\
\hline 21 & 87 & $\mathrm{~F}$ & 2 & 0 & 0 & 3 & 7.20 & 9.55 & 8.07 & 36.1 & IAC, $\operatorname{Rad}$ & $\mathrm{D}$ & 22 \\
\hline 22 & 89 & $\mathrm{~F}$ & 3 & 0 & 0 & 3 & 4.15 & 6.85 & 4.87 & 29.8 & IAC, $\operatorname{Rad}$ & A & 39 \\
\hline 23 & 70 & M & 4 & 0 & 0 & 2 & 2.65 & 4.30 & 3.20 & 28.4 & Chem, Ope & A & 17 \\
\hline 24 & 84 & $\mathrm{~F}$ & 2 & 0 & 0 & 2 & 7.55 & 9.15 & 8.50 & 23.0 & IAC, $\operatorname{Rad}$ & $\mathrm{D}$ & 5 \\
\hline 25 & 68 & $\mathrm{~F}$ & 2 & 0 & 0 & 3 & 6.95 & 9.80 & 7.37 & 40.3 & IAC, $\operatorname{Rad}$ & A & 73 \\
\hline 26 & 73 & M & 2 & 0 & 0 & 3 & 7.25 & 9.21 & 8.02 & 32.8 & IAC, $\operatorname{Rad}$ & A & 59 \\
\hline 27 & 63 & M & 2 & 3 & 0 & 3 & 6.74 & 11.13 & 9.74 & 27.9 & Chem & $\mathrm{D}$ & 5 \\
\hline 28 & 42 & M & 2 & 0 & 0 & 3 & 4.10 & 5.20 & 4.25 & 38.8 & Chem, Rad, Ope & A & 93 \\
\hline 29 & 54 & M & 2 & 0 & 0 & 3 & 5.69 & 8.82 & 6.95 & 30.2 & IAC, Rad, Ope & A & 71 \\
\hline 30 & 74 & M & 2 & 0 & 0 & 3 & 4.58 & 7.24 & 5.48 & 35.8 & IAC, $\operatorname{Rad}$ & A & 43 \\
\hline 31 & 68 & $\mathrm{~F}$ & 2 & 1 & 0 & 3 & 8.22 & 11.08 & 9.90 & 18.3 & IAC, Rad, Ope & $\mathrm{D}$ & 36 \\
\hline 32 & 53 & M & 4 & 0 & 0 & 2 & 5.30 & 6.64 & 5.36 & 10.0 & Chem, Ope & $\mathrm{D}$ & 46 \\
\hline 33 & 81 & M & 2 & 0 & 0 & 3 & 7.56 & 11.84 & 9.32 & 41.4 & & $\mathrm{D}$ & 18 \\
\hline 34 & 76 & M & 2 & 0 & 0 & 3 & 8.61 & 11.83 & 10.80 & 41.4 & IAC, $\operatorname{Rad}$ & $\mathrm{D}$ & 23 \\
\hline 35 & 77 & $\mathrm{~F}$ & 2 & 0 & 0 & 3 & 6.32 & 9.43 & 7.82 & 40.0 & IAC, Rad & A & 46 \\
\hline 36 & 73 & M & 2 & 0 & 0 & 3 & 8.08 & 10.17 & 9.50 & 41.8 & IAC, Rad, Ope & A & 70 \\
\hline 37 & 80 & $\mathrm{~F}$ & 3 & 0 & 0 & 3 & 3.05 & 5.41 & 4.01 & 42.7 & IAC, $\mathrm{Rad}$ & A & 27 \\
\hline 38 & 83 & M & 2 & 0 & 0 & 2 & 4.04 & 7.03 & 5.61 & 28.1 & IAC, $\operatorname{Rad}$ & A & 29 \\
\hline 39 & 84 & M & 2 & 0 & 0 & 3 & 8.43 & 12.76 & 11.03 & 47.5 & & $\mathrm{D}$ & 4 \\
\hline 40 & 81 & M & 2 & 0 & 0 & 2 & 5.52 & 7.35 & 6.66 & 8.0 & IAC, $\operatorname{Rad}$ & $\mathrm{D}$ & 19 \\
\hline 41 & 77 & M & 2 & 0 & 0 & 3 & 5.38 & 7.50 & 6.52 & 21.3 & IAC, $\operatorname{Rad}$ & $\mathrm{D}$ & 33 \\
\hline 42 & 74 & M & 3 & 0 & 0 & 3 & 7.71 & 11.89 & 10.12 & 36.0 & IAC, $\operatorname{Rad}$ & A & 7 \\
\hline 43 & 77 & M & 2 & 0 & 0 & 2 & 6.09 & 9.55 & 7.31 & 13.3 & IAC, Rad, Chem & $\mathrm{D}$ & 46 \\
\hline 44 & 83 & M & 2 & 0 & 0 & 3 & 6.04 & 9.57 & 8.85 & 42.0 & IAC, $\operatorname{Rad}$ & $\mathrm{D}$ & 15 \\
\hline
\end{tabular}


Table 2

Correlation between pathological variables and NOR counts and MIB-1 LI

\begin{tabular}{|c|c|c|c|c|c|}
\hline & \multirow{2}{*}{$\begin{array}{c}\text { Patients } \\
(n)\end{array}$} & \multicolumn{3}{|c|}{ NOR counts } & \multirow{2}{*}{$\begin{array}{r}\text { MIB-1 L } \\
(\%\end{array}$} \\
\hline & & resling & proliferating & whole & \\
\hline All cases & 44 & 5.82 & 8.19 & 6.89 & 28.9 \\
\hline Grade 2 & 9 & 4.96 & 6.94 & 5.78 & 16.87 \\
\hline Grade 3 & 35 & 6.04 & 8.52 & 7.18 & $31.1^{* *}$ \\
\hline Stage $T_{2}$ & 34 & 5.08 & 7.23 & 5.96 & 28.2 \\
\hline Stage $T_{34}$ & 10 & 6.04 & 8.48 & 7.17 & 29.1 \\
\hline Stage $N_{0} M_{0}$ & 40 & 5.697 & 8.01 & 6.707 & 29.4 \\
\hline Stage $\mathrm{N}_{1.3} \mathrm{M}_{1}$ & 4 & $7.19\rfloor^{*}$ & 10.07 & $8.78^{]^{* *}}$ & 23.7 \\
\hline
\end{tabular}

A

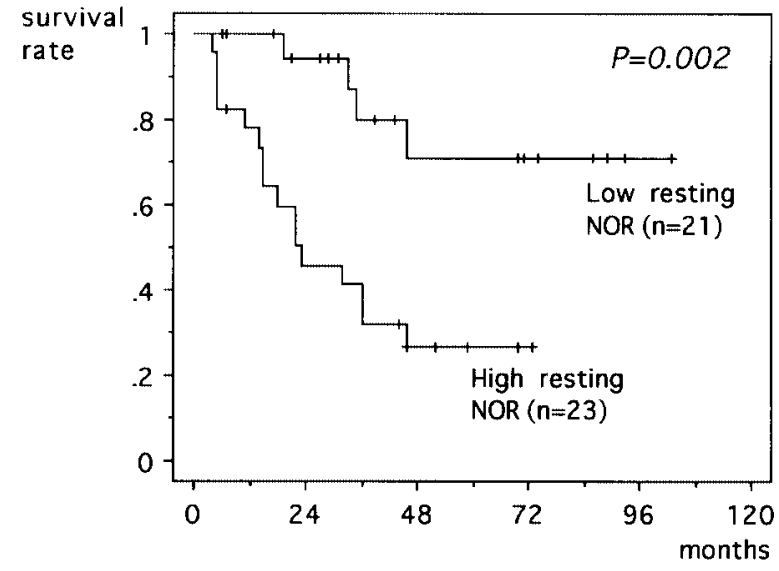

B

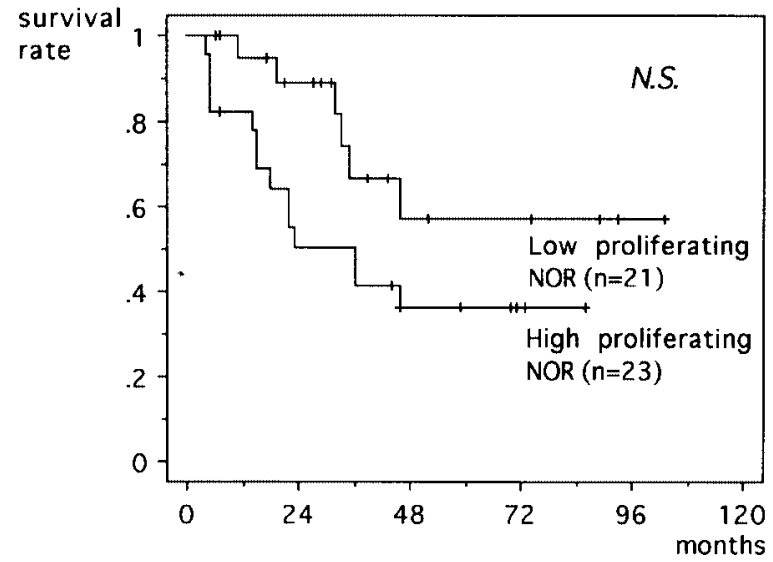

Fig. 2. Survival curves in patients with invasive bladder tumor. Higher survival rate is observed in patients with a low resting NOR tumor compared with those with high resting NOR tumor ( $p=0.002$ ) (A). No significant difference is observed in survival rate between the high proliferating NOR group and the low proliferating NOR group (B).
Table 3

Comparison of the prognosis using univariate and multivariate analysis for survival

\begin{tabular}{lllc}
\hline Variable & \multicolumn{2}{c}{ Univariate } & \multicolumn{2}{c}{ Multivariate } \\
\cline { 2 - 4 } & $p$-value & $p$-value & $\begin{array}{c}\text { Hazard } \\
\text { ratio }\end{array}$ \\
\hline Grade $(2 / 3)$ & 0.075 & 0.144 & 0.415 \\
Stage $\left(\mathrm{T}_{2} / \mathrm{T}_{3-4} / \mathrm{N}_{1-3} \mathrm{M}_{1}\right)$ & $0.009^{*}$ & 0.352 & 1.912 \\
resting NOR (low/high) & $0.002^{*}$ & $0.025^{*}$ & 5.291 \\
proliferating NOR (low/high) & 0.070 & 0.912 & 1.077 \\
MIB-1 LI (low /high) & 0.053 & 0.408 & 0.613 \\
\hline
\end{tabular}

* Statistically significant.

quires the detection and accurate assessment of the tumor's biological potential.

Intense research efforts are being made to identify and characterize true biological potential in the various bladder tumors. Proliferating antigens (Ki-67, PCNA), oncogenes (c-H-ras, c-myc, c-erbB-2), peptide growth factors (EGF, FGF, TGF) and their receptors, cell adhesion molecules (E-cadherin, Integrins), matrix metalloproteinase, tumor angiogenesis and angiogenesis inhibitors, and cell cycle regulatory proteins (p53, pRB, p21) have been recently identified [1]. Mutations in the p53 gene which functions as a tumor suppressor gene are the most common genetic alteration in human tumors [20]. The p53 overexpression determined by an immunohistochemical technique is an important prognostic indicator for bladder tumor progression [21]. A significant association was observed between decreased expression of E-cadherin and its associated proteins and poor prognosis of patients with bladder tumor [22]. Despite significant progress in the development and evaluation of various tumor markers, it is not yet possible to make solid recommendations about markers in the management of bladder tumor [1].

Simultaneous staining of AgNOR and Ki-67 using MIB-1 antibody was first reported by Munakata and Hendricks in paraffin embedded tissue of the ton- 
sil [23]. In the study by Bigras et al., they described that the AgNOR content in proliferating cell represented tumor proliferation activity and might correlate with cause specific survival period of the patient [11]. We have previously demonstrated the simultaneous staining of AgNOR and MIB-1 and have shown that proliferating NOR had a predictive value for tumor recurrence in superficial bladder tumors [13]. In the present study, although the difference between the proliferating and resting NOR was statistically significant $(p<0.01)$, the proliferating NOR was not a prognostic marker in invasive bladder tumor. Although the significance as a prognostic marker is still controversial, the resting NOR had a predictive value for survival in these patients. Similarly, Smith et al. performed sequential staining of AgNOR and PCNA in non-Hodgkin's lymphomas and normal tonsil tissues [24]. They described that the AgNOR count in PCNA positive cells was higher than that in PCNA negative cells, indicating that the number of AgNOR was associated with cell proliferation. Furthermore, the AgNOR count in PCNA negative cells in lymphomas was higher than that in normal tonsils, especially in the high grade lymphomas. It was described that the number of AgNOR may correlated with not only cell proliferation but also any other malignant potentials [24]. Nagao et al. reported a double staining of AgNOR and $\mathrm{Ki}-67$ in the patients with hepatocellular carcinoma (HCC) [9]. They described that AgNOR count in resting cells significantly correlated with histological grade in the patients with HCC, whereas AgNOR count in proliferating cells did not correlate. This reports may justify our present results indicatingly that elevation of the resting NOR count correlated with poor prognosis of patients with invasive bladder tumor. This suggested that resting NOR exclusively reflect the malignant potential of cells such as invasion or metastasis and might be useful as a new prognostic factor in patients with invasive bladder tumor.

Although several papers have demonstrated that the fraction of AgNOR depending on the types or numbers of AgNOR dots reflects tumor behavior [25,26], our present method is more reasonable for demonstrating tumor aggressiveness by AgNOR. It will be of interest to investigate correlations in other markers, such as protease expression, cell adhesion molecules, angiogenesis, between proliferating and resting cells. The simultaneous staining procedure is more complicated than AgNOR or MIB-1 staining alone, although it may still be an easier and quicker technique than current molecular biological analyses, such as p53, Rb, and c-
erb-B2 genes [27,28]. Furthermore, image analysis of AgNOR should be done to evaluate easier and more reproducible [29]. Although further studies are needed, the data presented here suggest that resting NOR can be a useful prognostic marker for select patients with invasive bladder tumor at a risk of poor prognosis. Hopefully, it will be possible to use the simultaneous staining techniques to select patients who should take more aggressive adjuvant therapy after radical cystectomy.

\section{References}

[1] J.P. Stein, G.D. Grossfeld, D.A. Ginsberg, D. Esrig, J.A. Freeman, A.J. Figueroa, D.G. Skinner and R.J. Cote, Prognostic markers in bladder cancer: a contemporary review of the literature, J. Urol. 160 (1998), 645-659.

[2] D. Hernandez-Verdun, J. Hubert, C.A. Bourgeois and M. Bouteille, Ultrastructural localization of AgNOR stained proteins in the nucleolus during the cell cycle and in other nucleolar structures, Chromosoma 79 (1980), 349-362.

[3] T. Shimazui, Y. Uchiyama, K. Uchida, K. Hattori, A. Takahashi, H. Akaza and K. Koiso, Evaluation of nucleolar organizer regions in human bladder cancers by light- and electronmicroscopic morphometry, Eur. Urol. 34 (1998), 441-447.

[4] J.C.E. Underwood and D.D. Giri, Nucleolar organization regions as diagnosis discriminants for malignancy, J. Pathol. 155 (1988), 95-96.

[5] M. Derenzini, A. Pession, F. Farabegoli, D. Trere, M. Badiali and P. Dehan, Relationship between interphasic nucleolar organizer regions and growth rate in two neuroblastoma cell lines, Am. J. Pathol. 134 (1989), 925-932.

[6] A. Pich, L. Chiusa and E. Margaria, Role of the argyrophilic nucleolar organizer regions in tumor detection and prognosis, Cancer Detect. Prev. 19 (1995), 282-291.

[7] P.K. Lipponen, M.J. Eskelinen and S. Nordling, Nucleolar organizer regions (AgNORs) as predictors in transitional cell bladder cancer, Br. J. Cancer 64 (1991), 1139-1144.

[8] S. Zambelli, A. Zanin, A. Gaglio, G. Zai, E. Bosco, A. Andrion and C. Magnani, Ki-67 scores and AgNor counts in transitional cell carcinoma of the bladder: apparent lack of prognostic value, Arch. Ital. Urol. Androl. 65 (1993), 665-670.

[9] T. Nagao, Y. Ishida, K. Yamazaki and Y. Kondo, Nucleolar organaizer regions in hepatocellular carcinoma related to the cell cycle, cell proliferation and histologic grade, Path. Res. Pract. 191 (1995), 967-972.

[10] J. Gerdes, U. Schwab and H. Lemke, Production of a mouse monoclonal antibody reactive with a human nuclear antigen associated with cell proliferation, Int. J. Cancer 31 (1983), 1320.

[11] G. Bigras, R. Marcelpoil, E. Brambilla and G. Brugal, Interest of targeting AgNORs measurement in cycling cells: in vivo cell kinetic evaluation of non-small cell lung cancer, Anal. Cell. Pathol. 11 (1996), 183-198. 
[12] A. Pich, L. Chiusa, A. Comino and R. Navone, Cell proliferation indices, morphometry and DNA flow cytometry provide objective criteria for distinguishing low and high grade bladder carcinomas, Virchows Arch. 424 (1994), 143-148.

[13] M. Tomobe, T. Shimazui, K. Uchida, S. Hinotsu and H. Akaza, Argirophilic nucleolar organizer region in proliferating cell has a predictive value for local recurrence in superficial bladder tumor, J. Urol. 162 (1999), 63-68.

[14] L.H. Sobin and C. Wittekind, Urinary bladder cancer, in: TNM Classification of Malignant Tumours, 5th edn, International Union Against Cancer, Wiley-Liss, New York, 1997, pp. 187190.

[15] Japanese Urological Association, Japanese Society of Pathology, Histological grading, in: General Rule for Clinical and Pathological Studies on Bladder Cancer, Kanehara Publishing Co. Ltd., Tokyo, 1993, pp. 80-81.

[16] E.G. Kaplan and P. Meier, Nonparametric estimation from incomplete observations, J. Am. Stat. Assoc. 53 (1958), 457-481.

[17] D.R. Cox, Regression models and life-tables, J. R. Stat. Soc. B 34 (1972), 187-220

[18] M.S. Soloway, Intravesical therapy for bladder cancer, Urol. Clin. North Am. 15 (1988), 661-672.

[19] D.G. Skinner and G. Lieskovsky, Management of invasive and high-grade bladder cancer, in: Diagnosis and Management of Genitourinary Cancer, W.B. Saunders, Co., Philadelphia, 1988, pp. 295-312.

[20] M. Hollstein, D. Sidrandky, B. Volgelstein and C.C. Harris, p53 mutations in human cancers, Science $\mathbf{2 5 3}$ (1991), 49-53.

[21] D. Esrig, D. Elmajian, S. Groshen, J.A. Freeman, J.P. Stein, S.C. Chen, P.W. Nichols, D.G. Skinner, P.A. Jones and R.J. Cote, Accumulation of nuclear $\mathrm{p} 53$ and tumor progression in bladder cancer, New Engl. J. Med. 331 (1994), 1259-1264.
[22] T. Shimazui, J.A. Shalken, L.A. Giroldi, C.F.J. Jansen, H. Akaza, K. Koiso, F.M.J. Debruyne and P.P. Bringuier, Prognostic value of cadherin-associated molecules $(\alpha-, \beta$-, and $\gamma$-catenins and $\left.\mathrm{p} 120^{\mathrm{cas}}\right)$ in bladder tumors, Cancer Res. 56 (1996), 4154-4158.

[23] S. Munakata and J.B. Hendricks, A multilabeling technique for simultaneous demonstration and quantitation of Ki-67 and nucleolar organizer regions (AgNORs) in paraffin-embedded tissue, J. Histochem. Cytochem. 42 (1994), 789-793.

[24] F.G. Smith, P.G. Murray and J. Crocker, Correlation between PCNA and AgNOR scores in non-Hodgkin's lymphomas using sequential staining technique, J. Clin. Pathol. 46 (1993), 2831.

[25] H. Shiina, H. Shirakawa, H. Yokogi, H. Kishi, M. Mizutani, M. Igawa and T. Ishibe, Clinical value of argyrophilic organizer region in bladder transitional cell carcinoma, Urol. Int. 54 (1995), 74-79.

[26] E.C.M. Ooms and R.W. Veldhuizen, Argyrophilic proteins of the nucleolar organizer region in bladder-tumors, Virchows Archiv. A 414 (1989), 365-369.

[27] D. Sidransky, A. Von-Eschenbach, Y.C. Tsai, P. Jones, I. Summarhayes and F. Marshall, Identification of p53 gene mutations in bladder cancers and urine samples, Science 252 (1991), 706709

[28] O. Yoshida, T. Habuchi and O. Ogawa, Recent advances in the molecular genetics of urogenital tumors, Int. J. Urol. 1 (1994), $1-16$.

[29] D. Ofner, M. Aubele, S. Biesterfeld, M. Derenzini, J.A. Giminez-Mas, P. Hufnagl, D. Ploton, D. Trere and J. Ruschoff, Guidelines of AgNOR quantification - first update, Virchows Arch. 427 (1995), 341 


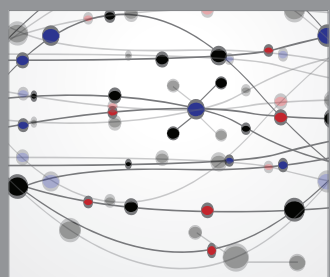

The Scientific World Journal
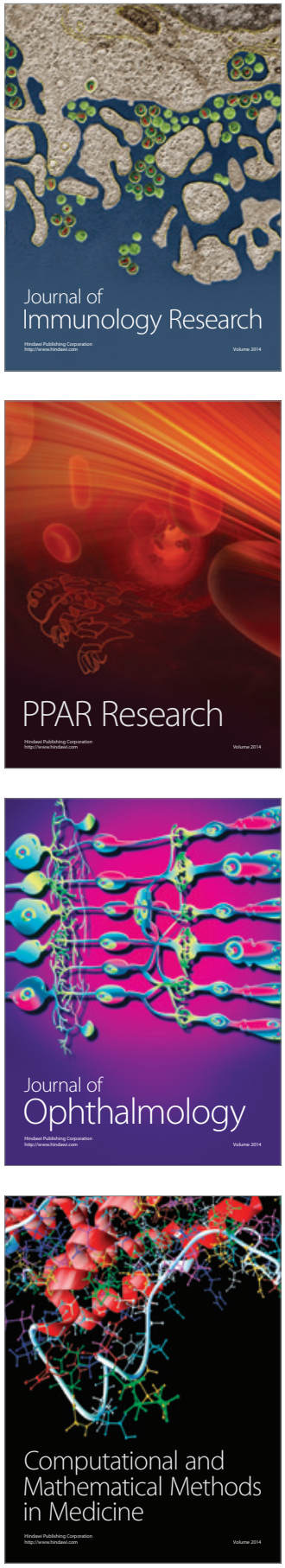

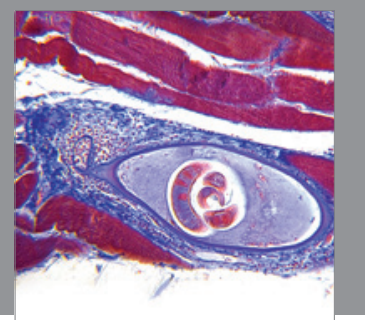

Gastroenterology

Research and Practice
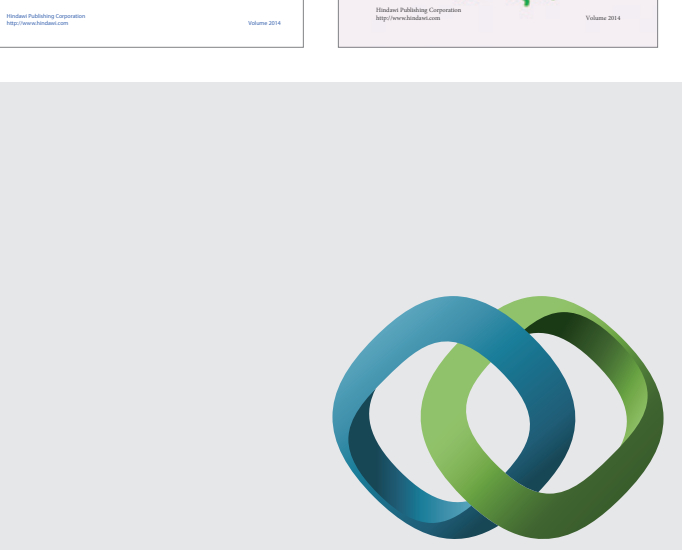

\section{Hindawi}

Submit your manuscripts at

http://www.hindawi.com
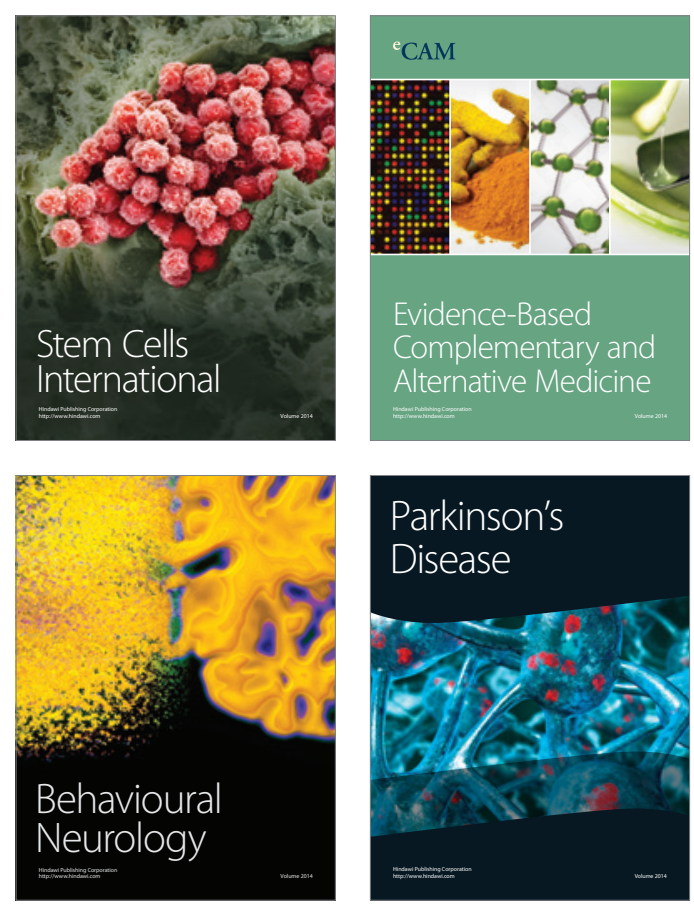

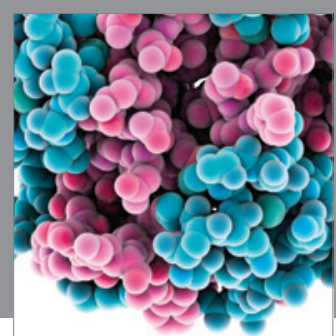

Journal of
Diabetes Research

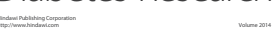

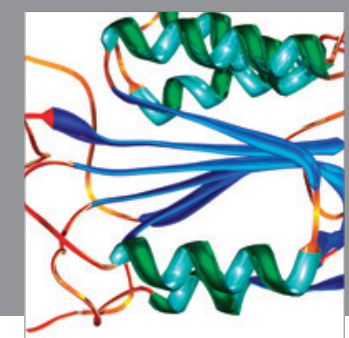

Disease Markers
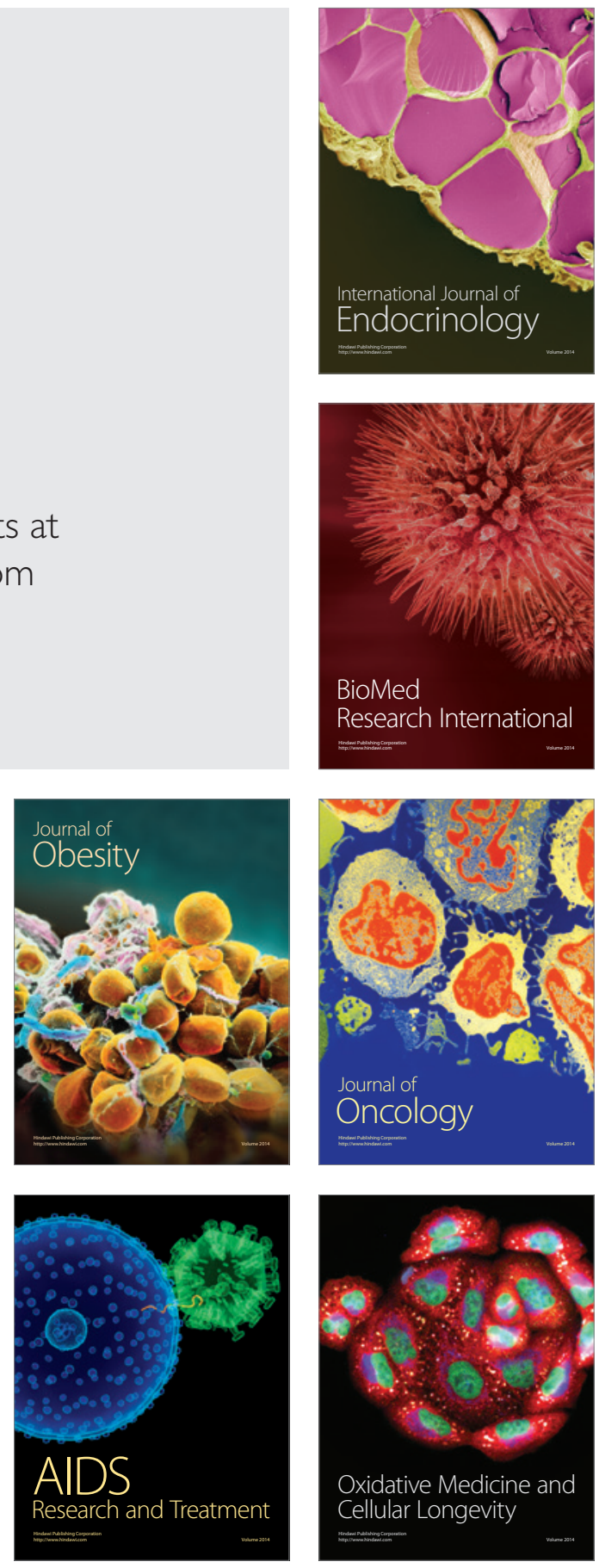